Physical characteristics and the talent identification and development processes in male youth soccer: A narrative review

$$
\text { Adam L. Kelly }{ }^{1} \text { and Craig A. Williams }{ }^{2 *}
$$

${ }^{1}$ Faculty of Health, Education and Life Sciences, Birmingham City University, Birmingham, West Midlands, United Kingdom, ${ }^{2}$ College of Life \& Environmental Sciences, University of Exeter, Children's Health and Exercise Research Centre, Exeter, Devon, United Kingdom

*Correspondence: Prof. Craig A. Williams, Children's Health and Exeter Research Centre (CHERC), University of Exeter, St Luke's Campus, Heavitree Road, EX1 2LU.c.a.williams@exeter.ac.uk 


\title{
Physical characteristics and the talent identification and development processes in male youth soccer: A narrative review
}

\author{
Adam L. Kelly ${ }^{1}$ and Craig A. Williams ${ }^{2 *}$ \\ ${ }^{1}$ Faculty of Health, Education and Life Sciences, Birmingham City University, Birmingham, \\ West Midlands, United Kingdom, ${ }^{2}$ College of Life \& Environmental Sciences, University of \\ Exeter, Children's Health and Exercise Research Centre, Exeter, Devon, United Kingdom \\ *Correspondence: Prof. Craig A. Williams, Children's Health and Exeter Research Centre \\ (CHERC), University of Exeter, St Luke's Campus, Heavitree Road, EX1 2LU. \\ c.a.williams@exeter.ac.uk
}




\title{
Physical characteristics and the talent identification and development processes in male youth soccer: A narrative review
}

\begin{abstract}
Talent identification and development in male youth soccer are complex and multidimensional processes. The English FA 'Four Corner Model' is often adopted by academies to support coaches and practitioners to implement a multidisciplinary approach to their talent identification and development framework. This holistic approach is characterised by Technical/Tactical, Psychological, Social, and Physical attributes, which are central to academy recruitment and individual long-term athlete development. The aim of this narrative review is to provide a critical synthesis of the Physical characteristics within this model, which facilitate talent identification and development; namely physical performance, growth and maturation, and the relative age effect.
\end{abstract}

Keywords: Elite youth football; Academy football; Physical performance; Growth and maturation; Relative age effect; Nature versus nurture

\section{Introduction}

How do talented children become adult experts and professionals? Both the identification of talent and the development of expertise amongst musicians, artists, academics, and athletes have interested researchers for decades $(26,32,53,90)$. The identification of young athletes with the potential to develop, and then subsequently excel during adulthood in their specialist sport, remains one of the major contemporary challenges for national governing bodies, sports clubs, coaches, and practitioners (76). Within youth soccer, talent identification and development strategies have become pivotal to organisations, especially with the pursuit for more sciencebased evidence to justify these support systems. Whilst talent identification and development are often used interchangeably, they are different processes. Talent identification can be described as recognising individuals with the potential to achieve expertise in a particular sport, 
whilst talent development can be considered as providing the most appropriate learning environment to realise potential $(105,111)$. The complex process of recognising, developing, and progressing youth soccer players through academies into senior professional players has been enhanced over the last decade, with the implementation of contemporary multidisciplinary paradigms being a mandatory requirement in England $(81,99)$.

One such example is the development and incorporation of the Elite Player Performance Plan (EPPP) amongst professional soccer academies in England (86). The EPPP policy provides recommendations for the multifaceted components of player development, with adherence to these standards assessed to categorise each academy in return for financial investment (99). Although the EPPP facilitates context and environmental specific approaches (which are logically warranted), these prescriptions are non-specific in their design and open to interpretation, thus allowing academies to adapt and adopt their own 'best-practice' strategies. The English FA Four Corner Model (98) offers a holistic approach, which is often adopted by professional academies to adhere to regulations outlined in the EPPP to support player development, characterised by Technical/Tactical, Psychological, Social, and Physical attributes. This model also formulates the delivery of the national coach education curriculum in England $(96,98)$ and underpinning the 'DNA Philosophy' of the England national player development pathway and performance strategy $(97,98)$. Academy philosophies are a crucial element in the talent identification and development processes in youth soccer as their implementation, via coaches' and specialist support staff, have a significant impact on individual recruitment, progression, and subsequent achievement (19). The current professionalised expansion of soccer academies has coincided with a growth in departmental structures, most noticeably with sport science and medicine becoming a key feature (91). Previous research shows recruitment into and development within an academy setting is often achieved due to a number of selected physical qualities, such as physical dominance, early 
maturity offset, and an earlier birthdate $(40,78)$. Therefore, given the increasing systematic research and applied focus in youth soccer, the aim of this article is to provide a narrative review of the physical characteristics, which should be considered as part of the FA Four Corner Model in youth soccer, in relation to talent identification and development.

\section{Physical performance}

Physical performance measures provide an objective evaluation of young soccer players' athletic development (23). The observation of these physiological characteristics has received considerable interest from researchers concerning talent development $(45,61,87,89)$. For example, Williams et al. (112) conducted a three year study assessing the speed and jump performances of youth soccer players, and showed that the monitoring of these variables facilitated the prediction of progression in an academy setting. It was shown that sprint changes increased beyond the 'worthwhile' effect of $1 \%$ for $10 \mathrm{~m}$ and $30 \mathrm{~m}$ sprints, and $1.8 \%$ for jump performance during the early teenage years. Previously, Mirkov et al. (80) had shown explosive muscle power, agility, and coordination were strongly associated with chronological age in academy soccer players aged 11 to 14 years. These data revealed the positive effect of age on physical performance within a developmental environment in academy soccer.

Gil et al. (37) indicated agility was the only physical performance factor that distinguished talented Spanish soccer players in the under-15 to 17 age groups, whilst also observing that players promoted to the under-14 age group were faster in a $30 \mathrm{~m}$ sprint test compared to non-promoted peers, suggesting that fitness characteristics may be discriminative functions of different chronological age groups. Le Gall et al. (61) also proposed that several fitness characteristics, including measures assessed by the countermovement jump (CMJ) and $40 \mathrm{~m}$ sprint, may determine the likelihood of players proceeding to higher standards of soccer in international youth players at under-14 and 16 age groups. Additionally, Gil et al. (34) found 
that pre-selected under-10 outfield players from a professional soccer academy performed better in velocity (i.e., $30 \mathrm{~m}$ sprint) and jumping (i.e., CMJ) tests compared to non-selected players. However, whilst Gil and colleagues collected anthropometric data, which highlighted how non-selected players were relatively younger and heavier, results were not adjusted for biological maturity, thus it is proposed that further investigation to determine whether this was a confounding factor surrounding the selection process should be initiated.

From a longitudinal perspective, Gonaus and Muller (40) conducted a ten year study using physiological data to predict future career progression in $14(n=410), 15(n=504), 16$ $(n=456)$, and 17-year-old $(n=272)$ Austrian academy soccer players. They revealed a combination of physiological variables are useful for discriminating 'drafted' national youth team players against their 'non-drafted' peers, with soccer-specific speed and upper limb power appearing to be the greatest predictors, through successfully classifying 62.7 to $66.2 \%$ of the players. Deprez et al.'s (22) retrospective study on 388 Belgian youth soccer players found that participants who attained a professional contract jumped further and had faster $5 \mathrm{~m}$ sprint times compared to non-contracted players. They summarised the importance of including the evaluation of physical performance characteristics between the ages of 8 to 16 years and its ability to distinguish high-level soccer players who progressed and succeeded within an academy environment.

Emmonds et al. (25) continued the investigation as to whether speed and endurance characteristics influenced obtaining a professional contract at aged 18 years. This longitudinal study measured physical characteristics in 443 academy soccer players over a seven year period, revealing that significant differences were only observed between professional and academy players for the $10 \mathrm{~m}$ and $20 \mathrm{~m}$ sprint at under-16 and under-18s, whilst intermittent endurance was only a discriminating factor at under-18s. Consequently, Emmonds and colleagues proposed physical assessments should be used for monitoring physical development 
rather than talent identification purposes. To further investigate physical performance, combined with technical skills, Gouvea et al. (44) used the dribbling skill test and shuttle dribble test to sub-divide 62 skilled and less-skilled youth soccer players aged 11 to 17 years. Gouvea and colleagues showed skilled performers possessed a higher practice time, greater situp performance, squat jump, CMJ, and Yo-Yo IE1 test compared to their less-skilled peers. These results indicate technical performance may be associated with a greater time of practice and physical capabilities. Consequently, this research data highlights the importance of applying sprint, agility and power characteristics to a battery of physical performance tests throughout academy age groups (i.e., under-9 to 23s), which already appears to be common practice amongst professional soccer academies $(54,91,95)$. A regular feature of most studies is the lack of a control group who are not soccer or sports training, so to ascertain what might be the normal or average change in these variables. Additionally, the above studies are not able to distinguish between what is the growth/maturational effect compared with that of the training adaptations. Therefore, any change scores in measurements must be viewed as growth, maturation, and responses to training effects.

In contrast to research that shows superior physical characteristics are positively associated with greater performance and progression within youth soccer, other studies have reported similar physical performance capacities between 'elite' and 'non-elite' populations. For example, Carling and colleagues $(13,14)$ reported comparable physical characteristics, including vertical jump and speed, in future professionals and non-professionals when tested at aged 13 years. In addition, Martinez-Santos et al. (74) focussed on the final period of a player's progression to professional soccer in Spain, showing that sprint and jump performances did not determine the promotion to professional status. However, part of the equivocal results between studies is the influence of maturational status, training exposure, or even nutritional status between players, as this is often not considered in many comparisons of 
physical performance. Table 1 provides a summary of some of the key literature focussing on physical performance and the talent identification and development processes in male youth soccer.

\section{***Table 1 near here***}

Despite the variance within physical performance studies, relative to specific characteristics that facilitate talent identification and development (51), a consensus supports the discrimination of greater physical abilities as soccer players' progress their professional careers compared to players of a lower non-professional standard. This observation reinforces the importance of recognising and promoting talented youth soccer players physical abilities (45). It is also important to recognise current approaches to monitoring and developing physical capabilities, such as adjusting comparisons in relation to maturity status, and conducting strength and conditioning regimes according to biological age compared to traditional chronological age grouping $(62,86)$. Further research is required to recognise whether soccer academies simply identify and recruit players who possess superior physical characteristics (i.e., very fast, powerful, or agile) at a young age, and then subsequently those players develop at the same rate as those who are not selected, or does the academy environment provide additional progression?

It is also noteworthy to recognise a small but accumulative amount of research that is examining the association between genetics and physical performance in soccer $(4,24,27,79,94)$. For example, it has been reported that Spanish and Lithuanian professional soccer players had a significantly higher percentage of the $A C E$ I/D gene variants, which has been shown to explain a greater sprint time variance, when compared to non-athletic population $(38,57)$. However, currently all the genetic studies investigating physical performance are considered largely preliminary and speculative, with greater sample sizes needed and further replication required. In addition, despite early evidence amongst senior professional soccer 
players, no research has yet investigated nor reported the influence of genetic factors on physical performance as part of the talent development process. A recent systematic review into talent identification and development in male soccer by Sarmento et al. (92) suggested that one of the most debated topics in this particular area, namely the genetic influence, has not been studied in youth soccer players. Therefore, practitioners working within a youth soccer environment are recommended to act with caution before considering to apply genetic factors, as part of their testing battery, to inform and interpret physical capabilities.

From an applied perspective, as part of the introduction of the EPPP, standardised performance testing is completed in England within professional soccer academies (99). This testing battery generally includes tests for sprint abilities (30 m sprint test), explosive power (CMJ), and agility (505 agility test), to create a physical profiling methodology to support individual physical development. However, whilst this testing battery is common practice amongst professional academies, further research is required to examine the potential benefits and pitfalls of these particular testing protocols within specific age-phases. Allied to this practice, the academy test-retest reliability of such methods, in order to validate their inclusion into an academy programme, are required (95).

\section{Growth and maturation}

While growth and maturation are often used interchangeably, they are different constructs. Growth refers to the development of measurable changes in body size, such as stature, body mass, and body fat percentage (67). Maturation refers to qualitative system changes, both structural and functional, in the body's progress to maturity, such as appearance of pubic hair (14) or the closing of the epiphyseal plates of long bones (70). The process of maturation including both the timing (e.g., the age at maximum growth in height during the adolescent growth spurt) and the tempo (the rate at which maturation progresses) is important, given that 
all the biological systems in the body will occur at different rates (70). Differences in growth and maturation can be considerable, with regular terms described as early, on-time, or late 'maturers' (85). For example, within an under-13 chronological age group, it is possible to have two players with the same chronological age but as much as five years difference in biological skeletal age $(43,70)$. Therefore, individual increases in physical performance, such as speed, power, agility, and endurance, will occur at different chronological ages (62). Thus, a player's earlier growth and maturity status, relative to other same age peers, will possess advantages in physical and physiological performance measures, which often leads to systematic selection and progression of more mature players $(43,78)$. It should also be noted that early maturing males also generally experience a more intense pubertal growth spurt and in addition to maturing earlier, they also tend to experience greater gains in size, lean mass and muscle strength, further accentuating this advantage (12). Consequently, these early maturing players are likely to be more successful than their less mature peers, who may be regarded as less 'gifted' or 'talented' during the talent selection process, or drop out due to low confidence or lack of success (28). However, whilst early maturers are at an advantage due to their physical size at an early age, once each player's maturation starts to plateau towards adulthood, the presented physical advantage is often reduced (68). Thus, it could be questioned whether identifying players at an early age who possess advanced growth and maturation status is truly reflective of an effective talent identification philosophy (10).

Thus, similarly to the existing EPPP guidelines, it is proposed that growth and maturation data should be collected, as it offers the opportunity to monitor physical development, whilst also supporting academies to relate it more effectively to aspects such as training load and strength and conditioning programmes. For example, although there is no one method to precisely predict how tall a child will become, the Khamis-Roche method can be used to provide an acceptable estimate $(59,60)$. As well as a predictor of adult height, the 
Khamis-Roche method also provides the percentage of predicted adult height attained and peak-height velocity (PHV) status (pre-, circa- or post-PHV). This provides median values for the equivalent errors in males from aged 4 to 17.5 years, which are 0.85 inches and 2.10 inches, respectively. (60). Whilst there are other methods to calculate similar predictions (e.g., the maturity offset method), the Khamis-Roche formula appears to be widely applied within the soccer development environment to monitor growth and maturation and facilitate individual training programmes $(60,70)$. This method offers a useful tool to complement a physical approach relating to talent identification and development in youth soccer $(60,70)$. However, it is important to understand there are external validity and reliability limitations of any approach to systematically monitor maturity. Specific limitations include the large proportion of existing datasets conducted with North American and Caucasian youth (9), which contrasts with other ethnic groups that comprise academy squads; issues related to a slight deterioration in accuracy prediction $(65,66)$; the consistency of informed protocols (i.e., ISAK); and the requirement of qualified practitioners to accurately obtain data $(65,66)$.

Compared to same-age but non-sporting populations, youth soccer players possess greater values for stature and body mass, whilst also usually being earlier maturers; particularly during adolescence and within talent development programmes $(67,68)$. Previous research has investigated the difference between performance level in youth soccer and growth related variables $(67,113)$. For example, Malina and colleagues (64) have shown how inter-individual differences in physical growth, biological maturation, interactions with peers, and behavioural changes persuaded youth coaches, clubs, and federations to identify and recruit youth soccer players with advanced growth and maturation status. Moreover, lower baseline anthropometric measures have generally been associated in youth soccer players who either drop out (28) or who were not selected to play at the next level $(34,36)$, compared to their higher baseline peers who move to a higher playing standard. Le Gall et al. (61) replicated similar findings showing 
'elite' youth soccer players who graduated from an academy and achieved professional status had advanced maturity status, greater body mass, and taller stature compared to those who did not become professional. It is important to acknowledge these physical attributes are not necessarily retained throughout maturation or are a guarantee to translate into expert performance during adulthood (105).

Whilst the majority of research have shown talent identification and development in youth soccer is characterised by a bias towards early maturation $(14,18,28,36,37,61,67,105)$, there are some contradictory findings. Franks et al. (30) investigated key factors for English national schoolboys who had or had not, achieved professional status and found no discriminating differences for anthropometric characteristics (i.e., stature, body mass, and body fat percentage). Ostojic et al. (84) has also shown 'elite' status in soccer to gradually exclude early maturing boys and favour late maturing boys as age increased, after following 48 boys aged 14 years playing in the Serbian youth soccer Division One over an eight year period. Ostojic and colleagues found that of the original sample of late maturing boys who made up $21 \%$ of the total sample at 14 years of age, $60.1 \%$ successfully transitioned to this level. Accordingly, the absolute proportion of late maturing boys represented in the elite level sample of 16 boys would be $\sim 38 \%$. While Ostojic's finding are encouraging news for the late maturing players, it is also important to recognise that the Tanner-Whitehouse 3 (TW3) method tends to underestimate skeletal age by about 0.5 years, compared to other indices (71). Hence, the number of late maturing boys in this study identified at 14 years is potentially overestimated, whilst the number of on-time and late maturing boys are potentially underrepresented. In addition, it remains unclear if these observations are due to a deliberate act of manipulating the selection and development of later maturing players or are an anomaly. Table 2 provides a summary of some of the key literature focussing on growth and maturation and the talent identification and development processes in male youth soccer. 
Vandendriessche et al. (108) demonstrated how, following the consistent findings of early maturing players gaining greater opportunities in 'elite' youth soccer, the Royal Belgian Football Association installed, besides their normal national youth teams (under-16 and under17), two future national teams comprising of on-time and late maturing players (under-16 Futures and under-17 Futures). This initiative aimed to develop the potential of these players according to their biological age and subsequently support issues with drop-out within the 'Futures' groups. Vandendriessche and colleagues research found growth and maturation status significantly affected physical and motor performance, thus highlighting the benefits of avoiding a one-dimensional chronological age approach, through analysing biological performance. Further strategies to support the development of later maturing players include the incorporation of banding players based on their biological age compared to the fixed chronological age groupings $(7,17)$. This grouping approach, commonly known as 'biobanding', clusters players based on their percentage of predicted adult height attained $(16,17,60)$. Therefore, players are playing against opponents with a similar growth and maturation status thus minimising physical advantages $(16,17,72)$. Players also reported greater opportunities to engage in leadership behaviours, influence game-play, and express themselves on the ball when compared to chronological age grouping $(11,16,72)$. Together, Vandendriessche et al. and Cumming et al. provide useful examples of strategies to support the development of younger and less mature youth soccer players. More recently Abbott and colleagues (2) found in 25 young players (11-15 years old) that bio-banded competition changed the technical demand placed upon them compared to chronological competition, but did not reduce the physical demands. It was concluded that bio-banded competition can be prescribed to athletes of different maturation groups dependent upon their particular developmental needs. 
While these factors regularly discriminate late maturing players during childhood and adolescence (68), later maturation appears to support equivocal long-term development if they are recognised and facilitated throughout the development process appropriately, compared to their early maturing peers (84). Using a child or adolescents' skeletal age alone to predict expertise at senior level may be considered naïve; however, existing literature shows that alongside that of age, late maturing players are increasingly underrepresented in academy soccer (56). Consequently, evidence indicates that there is no equivalent opportunity for late and early maturing players. Therefore, physical characteristics should remain an important measure as part of a multidisciplinary development pathway (88), so as to monitor the growth and maturation of talented youth soccer players throughout their development and into senior professional status. This method would strengthen research efforts to elucidate the sparsely investigated relationship between talent and late maturers. In addition, similarly to the recent efforts by the Premier League's EPPP, adopting a bio-banding format to match players based on biological age, as opposed to chronological age, may provide a useful tool to moderate the maturation bias and facilitate the development of later maturers (72). It should be noted however that bio-banding is part of a broader programme of the English Premier League and its associated partners and not a straight swap for age group competition.

\section{Relative age effect}

Whilst variances concerning chronological age of less than 12 months have little significance on adult physiques, they can have a large influence on young athletes during their sporting development (46). Early research by Barnsley et al. (5) showed a relative age effect (RAE) in ice hockey, revealing a strong linear relationship between the month of birth (from January to December) and the proportion of players in the youth leagues studied. That is, the number of players with birthdates in January was the highest, followed by a steady decline throughout the 
remainder of the selection year. Despite these historical findings, the RAE is (almost) ubiquitous in youth sport, having been demonstrated in athletics (52), Australian Rules football (106), baseball (83), basketball (20), cricket (77), dance (107), ice hockey (103), rugby league (101), rugby union (76), swimming (15), and tennis (104), amongst others. It is also important to recognise that RAEs can be observed during early childhood and often before a growth and maturation selection bias is prevalent (56).

The majority of RAE research in youth soccer has revealed that birthdate distribution has a significant impact on player identification and development $(39,42,46,47,49,58,75,78,82,110)$. For instance, early RAE research in a soccer context from Barnsley et al. (6) titled their study 'Family planning: Football style', to illustrate the benefits of being born earlier in a chronological year. In fact, youth soccer has featured predominantly at the fore of RAE research, with the majority of studies establishing birthdate distribution having a significant effect on player selection and progression (47). For example, Glamser and Vincent (39) discovered that, out of 147 American male 'elite' youth soccer players, almost $70 \%$ were born in the first half of the year (quartiles 1 and 2). A strong RAE in 'elite' youth soccer has also been established in Germany, Australia, Brazil, and Japan (amongst others), providing evidence that the effect is independent of different cut-off dates, such as January to December and September to August (49,82,110). Furthermore, Helson et al. (49) investigated birthdate distributions across ten European countries, using 2,175 age citations across under15, under-16, under-17, and under-18 age groups. Selection criteria included players representing national youth teams in international competitions or professional youth teams in international competitions. The results revealed an over-representation of players born in the first quarter for both the national and professional youth selections across all age groups, which again was independent of dissimilar cut-off dates. 
Helsen et al. (46) expressed their frustration illustrating ten years of research had made no impact on the structure of youth soccer involvement despite their initial concerns. Contemporary research still shows the occurrence of this phenomenon still exists at the highest levels of talent development in youth soccer. For example, Massa et al. (75) investigated 341 youth soccer players (aged 10 to 20 years) at the professional Brazilian soccer club Sao Paulo for their birthdate distributions. Results revealed a significantly higher percentage of athletes were born in the first quarter $(47.5 \%)$ compared to the fourth quarter $(8.8 \%)$. Furthermore, from a European perspective, Gonzalez-Villora et al. (42) found the RAE was not apparent in the UEFA Champions League for senior professional teams; however, it was present in the three youth categories (under-21, under-19, and under-17 age groups). Table 3 provides a summary of some of the key literature focussing on the RAE and the talent identification and development processes in male youth soccer.

\section{***Table 3 near here***}

In regard to moderating the RAE, Mann and van Ginneken (73) produced preliminary evidence for an intervention designed to reduce the RAE through applying an age-ordered shirt numbering system. They found that supporting talent scouts with the knowledge that the numbers on the playing shirts corresponded with the relative age of the players eliminated age bias. Furthermore, Bennett et al. (8) have suggested a mitigating tool of establishing a 'selection quota' whereby sporting organisations and talent development programmes are required to select a minimum number of athletes from each birth quarter (BQ). In addition, Tribolet et al. (102) proposed discouraging early deselection, particularly during adolescence, to allow continued exposure to higher-level coaching and resources without the option of being deselected. However, previous research has illustrated that repeated incidences of selection and deselection may be more beneficial to achieving senior professional status (50). Thus, further research is required to address whether the avoidance of deselection within a talent pathway is 
beneficial for achieving long-term expertise in soccer. In addition, future research should also

explore the implications and effectiveness of strategies, such as the age-ordered shirt numbering system, selection quota approaches, and discouraging early deselection, on moderating the RAE in youth soccer.

Currently, professional soccer clubs in England can begin to formally sign academy players at under-9, and 'talent' at this early stage tends to be identified as current ability in comparison to peers, leaving little thought surrounding the characteristics that support the subsequent long-term achievement of expertise as a senior athlete (63). As these players will form the core of each successive age group for the proceeding years, biases in selection into an academy (i.e., an earlier chronological birthdate) will subsequently dominate over a prolonged period. Therefore, since the purpose of an academy should be to identify and then develop young soccer players towards future performance abilities, attention should rather concentrate on those characteristics to manage the course of development, rather than focussing on current performance abilities that can be heightened through an early birth advantage (1).

It has been proposed that playing against relatively older athletes within their chronological age group, BQ3 and BQ4s have to develop certain technical proficiencies or tactical awareness to be able to counteract the physical bias $(31,33,54,76,77,93)$. From an applied perspective, a larger/stronger player may be able to easily dispossess a smaller/weaker opponent as a result of their physical dominance, thus a smaller/weaker player must create a technical or tactical solution to reduce this advantage. Ashworth and Heyndels (3) highlight how these younger/smaller players must overcome a talent development system that discriminates against chronologically younger players, through being more talented than their relatively larger peers to counteract their size advantage. Therefore, it has been suggested that BQ3 and BQ4s are more likely to be positively selected, whereby they are chosen from 'the right tail of the ability distribution' (31). 
Furthermore, whilst a smaller/weaker player may be physically inferior throughout their youth development, as a result of their younger age, once they 'catch-up' towards adulthood, the training adaptations and their development in certain psychological characteristics that previously allowed them to compete, now come to the fore (41). For example, Schorer et al. (93) discussed the 'underdog hypothesis', whereby the initial disadvantage may eventually contribute to the later superiority because earlier differences in age plateau and become less prevalent towards adulthood. This is potentially through learning to 'work harder', resulting in peer effects that facilitate resilience and enhanced motivation (93). Thus, these psychological benefits likely equip the chronologically younger players, or 'underdogs', to overcome subsequent obstacles and succeed at senior professional level (31).

Recent research in soccer specifically has proposed an 'underdog hypothesis'. For instance, Kelly et al. (58) demonstrated how there was a strong RAE within an English professional soccer academy, whereby BQ1s were almost three times more likely to be recruited compared to $\mathrm{BQ} 4 \mathrm{~s}$. However, when observing the conversion rate, their findings suggest BQ4s were four times more likely to achieve a professional contract once they were recruited into the academy. Similarly, whilst Gil et al. (35) found a significant overrepresentation of BQ1s compared to any other BQ throughout their Spanish professional soccer academy, they illustrated that the odds for $\mathrm{BQ} 4 \mathrm{~s}$ to achieve professional status were three times more likely compared to any other BQ. This observation indicates that although the RAE continues to manifest itself within professional soccer academies, once a chronologically younger player enters an academy (particularly as a BQ4), they have a significantly greater chance of graduating with a professional contract. Thus, it is recommended that coaches and practitioners should act with caution when creating strategies to eliminate the RAE, as doing so may also eradicate the 'underdog hypothesis'. This is likely achieved through removing the natural developmental outcomes through a 'rocky road' that is proposed for significantly 
younger players, whilst playing within their chronological age group (76). Conversely, there may be long-term negative effects of being a chronologically older player, as they may not be exposed to the same challenges as their younger peers. Thus, this effect should also be considered as part of future research studies (e.g., through strategies such as 'playing-up' a chronological age group), so as to understand why an early disadvantage may lead to greater opportunities.

So how do academies get the 'best of both worlds' with regards to moderating the RAE whilst also gaining the benefits of the underdog hypothesis (if at all possible)? Whilst current strategies appear unexplored, Kelly et al. (58) proposed future research could examine the effect of 'playing-up' a chronological age group, to facilitate for the early BQ player, greater development by creating a 'BQ4 effect' in an older age group. Consequently, this may also mediate the widely reported high dropout rates amongst earlier BQ players $(28,48)$, and provide a greater opening for more late birth quartiles to be selected into an academy. Likewise, 'playing-down' an age group may also offer a more suitable developmental setting for later BQ players, as they 'catch-up' with their chronologically older peers, whilst being afforded a more challenging environment for early birth quartiles within a younger age group. Thus, it is proposed academies adopt a 'flexible chronological age approach' to group young players by offering early birth quartiles (i.e., BQ1s) and late birth quartiles (i.e., BQ4s) the opportunity to play-up and play-down an age group respectively, as opposed to fixed traditional chronological bandings (58).

\section{Conclusion}

Advanced growth and maturation and an earlier birthdate are still dominant and are assumed as favourable for initial talent identification, although its determination to successfully predict a subsequent professional career remains inconclusive. In comparison, advanced physical 
performance, through fitness characteristics such as sprint ability, agility, and CMJ, appear to be more favourable predictors at youth academy level for achieving future senior professional status. Thus, due to the physical nature of soccer and its importance at the senior professional level, physiological data still provides valuable information and should be monitored within soccer academies, but as part of a multidisciplinary talent development approach. The published research surrounding physiological characteristics demonstrated early maturation is still also associated with greater physical performance, thus coaches and practitioners should be fully aware of status of an individual player's growth and maturity stage. Consequently, strategies and initiatives can be implemented to counteract or minimise its effect. These include practices to incorporate strength and conditioning programmes, training regimes, and matchplay strategies relative to biological age instead of chronological age.

Talent identification and development are complex and multidimensional processes in youth soccer, with the successful transition from youth academy level to senior professional status not dependent on one particular skill-set. For instance, whilst it is evident chronologically younger players are underrepresented in academy settings, the 'underdog hypothesis' highlights the potential positive long-term impact. This ultimately results in a higher drop-out of chronologically older players, which may be a result of not being subjected to the same psychological challenges to facilitate long-term development compared to their younger peers. Thus, whilst there appears to be an increasing amount of research that is applying a multidisciplinary approach to encompass the potential factors that support pathways towards expertise, the direction of future research within the 'physical corner' or the FA Four Corner Model still requires a better holistic approach. This approach will also require organisational structures to moderate such effects to ensure there is a continued emphasis on creating the right environment for every player to develop to their full potential. 


\section{Word count}

5,589 (including Title and Abstract above; excluding attached Tables and References below) 


\section{References}

1. Abbott A and Collins D. Eliminating dichotomy between theory and practice in talent identification and development: Considering the role of psychology. J Sports Sci 22: 395408, 2004.

2. Abbott W, Williams S, Brickley G, Smeeton NJ. Effects of Bio-Banding upon Physical and Technical Performance during Soccer Competition: A Preliminary Analysis. Sports. Aug;7(8):193, 2019.

3. Ashworth $\mathbf{J}$ and Heyndels B. Selection bias and peer effects in team sports: The effect of age grouping on earnings of German soccer players. J Sports Econom 8: 355-377, 2007.

4. Baker $\mathbf{J}$ and Horton S. A review of primary and secondary influences on sport expertise. High Abil Stud 15: 211-228, 2004.

5. Barnsley RH, Thompson AH, and Barnsley PE. Hockey success and birthdate: The relative age effect. CAHPER Journal 51: 23-28, 1985.

6. Barnsley RH, Thompson AH, and Legault PE. Family planning: Football style. The relative age effect in football. Int Rev Sociol Sport 27: 77-87, 1992.

7. Baxter-Jones ADG. Growth and development of young athletes: Should competition levels be age related? Sports Med 20: 59-64, 1995.

8. Bennett KJM, Vaeyens R, \& Fransen J. Creating a framework for talent identification and development in emerging football nations. Sci Med Football 3: 36-42, 2019.

9. Beunen GP, Malina RM, Lefevre J, Claessens AL, Renson R, and Simons J. Prediction of adult stature and noninvasive assessment of biological maturation. Med Sci Sports Exerc 29: 225-230, 1997.

10. Bidaurrazaga-Letona I, Lekue JA, Amado M, and Gil SM. Progression in youth soccer: Selection and identification in youth soccer players aged 13-15 years. J Strength Cond Res 33: 2548-2558, 2019.

11. Bradley B, Johnson D, Hill M, McGee D, Kana-ah A, Sharpin C, Sharp P, Kelly A, Cumming SP, and Malina RM. Bio-banding in academy football: Player's perceptions of a maturity matched tournament. Ann Hum Biol, 46(5), 400-408, -2019.

12. Brown KA, Patel DR, and Darmawan D. Participation in sports in relation to adolescent growth and development. Transl Pediatr 6: 150-159, 2017.

13. Carling C, Le Gall F, and Malina RM. Body size, skeletal maturity, and functional characteristics of elite academy soccer players on entry between 1992 and 2003. J Sports Sci 30: 1683-1693, 2012.

14. Carling C, Le Gall F, Reilly T, and Williams AM. Do anthropometric and fitness characteristics vary according to birth date distribution in elite youth academy soccer players? Scand J Med Sci Sports 19: 3-9, 2009. 
15. Cobley S, Abbott S, Dogramaci S, Kable A, Salter J, Hinterman M, and Romann M. Transient relative age effects across annual age groups in national level Australian swimmers. J Sci Med Sport 21: 839-845, 2018.

16. Cumming SP, Brown DJ, Mitchell S, Bunce J, Hunt D, Hedges C, Crane G, Gross A, Scott S, Franklin E, Breakspear D, Dennison L, White P, Cain A, Eisenmann JC, and Malina R. M. Premier League academy soccer players' experiences of competing in a tournament bio-banded for biological maturation. J Sports Sci 36: 757-765, 2018.

17. Cumming SP, Lloyd RS, Oliver JL, Eisenmann JC, and Malina RM. Bio-banding in sport: Applications to competition, talent identification, and strength and conditioning of youth athletes. Strength Cond J 39: 34-47, 2017.

18. Cumming SP, Searle C, Hemsley JK, Haswell F, Edwards H, Scott S, Gross A, Ryan D, Lewis J, White P, Cain A, Mitchell SB, and Malina RM. Biological maturation, relative age and self-regulation in male professional academy soccer players: A test of the underdog hypothesis. Psychol Sport Exerc 39: 147-153, 2018.

19. Cushion C, Ford PR, and Williams MA. Coach behaviours and practice structures in youth soccer: Implications for talent development. J Sports Sci 30: 1631-1641, 2012.

20. Delorme $\mathrm{N}$ and Raspaud M. The relative age effect in young French basketball players: A study on the whole population. Scand J Med Sci Sports 19: 235-242, 2009.

21. Deprez D, Fransen J, Boone J, Lenoir M, Philippaerts R, and Vaeyens R. Characteristics of high-level youth soccer players: Variation by playing position. J Sports Sci 33: 243-254, 2015.

22. Deprez D, Fransen J, Lenoir M, Philippaerts R, and Vaeyens R. A retrospective study on anthropometrical, physical fitness, and motor coordination characteristics that influence dropout, contract status, and first-team playing time in high level soccer players aged eight to eighteen years. J Strength Cond Res 29: 1692-1704, 2015.

23. Durand-Bush N and Salmela JH. The development and maintenance of expert athletic performance: Perceptions of world and Olympic champions. J Appl Sport Psychol 14: 154$171,2002$.

24. Egorova ES, Borisova AV, Mustafina LJ, Arkhipova AA, Gabbasov RT, Druzhevskaya AM, Astratenkova IV, and Ahmetov II. The polygenic profile of Russian football players. J Sports Sci 32: 1286-1293, 2014.

25. Emmonds S, Till K, Jones B, Mellis M, and Pears M. Anthropometric, speed and endurance characteristics of English academy soccer players: Do they influence obtaining a professional contract at 18 years of age? Int J Sports Sci Coach 11: 212-218, 2016.

26. Ericsson KA, Krampe RT, and Tesch-Roemer C. The role of deliberate practice in the acquisition of expert performance. Psychol Rev 100: 363-406, 1993.

27. Eynon N, Ruiz JR, Yvert T, Santiago C, Gomez-Gallego F, Lucia A, and Birk R. The $\mathrm{C}$ allele in NOS3-786 T/C polymorphism is associated with elite soccer player's status. Int J Sports Med 33: 521-524, 2012. 
28. Figueiredo AJ, Goncalves CE, Coelho-e-Silva MJ, and Malina RM. Characteristics of youth soccer players who drop out, persist or move up. J Sports Sci 27: 883-891, 2009.

29. Figueiredo AJ, Goncalves CE, Coelho-e-Silva MJ, and Malina RM. Youth soccer players, 11-14 years: Maturity, size, function, skill and goal orientation. Ann Hum Biol 36: 60-73, 2009.

30. Franks AM, Williams AM, Reilly T, and Nevill A. Talent identification in elite youth soccer players: Physical and physiological characteristics - Communication to the 4th World Congress on Science and Football, Sydney. J Sports Sci 17: 812, 1999.

31. Fumarco L, Gibbs BG, Jarvis JA, and Rossi G. The relative age effect reversal among the National Hockey League elite. PLoS One 12: e0182827, 2017.

32. Gagne F. Academic talent development and the equity issue in gifted education. Talent Dev Excell 3: 3-22, 2011.

33. Gibbs BG, Jarvis JA, and Dufur MJ. The rise of the underdog? The relative age effect reversal among Canadian-born NHL hockey players: A reply to Nolan and Howell. Int Rev Sociol Sport 47: 644-649, 2012.

34. Gil SM, Badiola A, Bidaurrazaga-Letona I, Zabala-Lili J, Gravina L, SantosConcejero J, Lekue JA, and Granados C. Relationship between the relative age effect and anthropometry, maturity and performance in young soccer players. $J$ Sports Sci 32: 479-486, 2014.

35. Gil SM, Bidaurrazaga-Letona I, Martin-Garetxana I, Lekue JA, \& Larruskain J. Does birth date influence career attainment in professional soccer? Sci Med Football, 1-8, 2019.

36. Gil SM, Gil J, Ruiz F, Irazusta A, and Irazusta J. Physiological and anthropometric characteristics of young soccer players according to their playing position: Relevance for the selection process. J Strength Cond Res 21: 438-445, 2007.

37. Gil SM, Ruiz F, Irazusta A, Gil J, and Irazusta J. Selection of young soccer players in terms of anthropometric and physiological factors. J Sports Med Phys Fitness 47: 25-32, 2007.

38. Gineviciene V, Jakaitiene A, Tubelis L, and Kucinskas V. Variation in the ACE, PPARGC1A and PPARA genes in Lithuanian football players. Eur J Sport Sci 14: 289-295, 2014.

39. Glamser FD and Vincent J. The relative age effect among elite American youth soccer players. J Sports Behav 27: 31-38, 2004.

40. Gonaus $\mathrm{C}$ and Muller E. Using physiological data to predict future career progression in 14- to 17-year-old Austrian soccer academy players. J Sports Sci 30: 1673-1682, 2012.

41. Gonzalez Bertomeu JF. Too late for talent to kick in? The relative age effect in Argentinian male football. Soccer Soc 19: 573-592, 2018.

42. Gonzalez-Villora S, Pastor-Vicedo JC, and Cordente D. Relative age effect in UEFA championship soccer players. J Hum Kinet 47: 237-248, 2015. 
43. Gouvea MAD, Cyrino ES, Ribeiro AS, Da Silva DRP, Ohara D, Valente-dos-Santos $\mathrm{J}$, Coelho-e-Silva MJ, and Ronque E. Influence of skeletal maturity on size, function and sport-specific technical skills in youth soccer players. Int J Sports Med 37: 464-469, 2016.

44. Gouvea MAD, Cyrino ES, Valente-dos-Santos J, Ribeiro AS, Silva DRPD, Ohara D, Coelho-e-Silva MJ, and Ronque ERV. Comparison of skilful vs. less skilled young soccer players on anthropometric, maturation, physical fitness and time of practice. Int J Sports Med 38: 384-395, 2017.

45. Hammani MA, Abderrahmane AB, Nebigh A, Le Moal E, Ounis OB, Tabka Z, and Zouhal $\mathrm{H}$. Effects of a soccer season on anthropometric characteristics and physical fitness in elite young soccer players. J Sports Sci 31: 589-596, 2013.

46. Helsen WF, Baker J, Michiels S, Schorer J, van Winckel J, and Williams MA. The relative age effect in European professional soccer: Did ten years of research make any difference? J Sports Sci 30: 1665-1671, 2012.

47. Helsen WF, Hodges NJ, van Winckel J, and Starkes JL. The roles of talent, physical precocity and practice in the development of soccer expertise. J Sports Sci 18: 727-736, 2000 .

48. Helsen WF, Starkes JL, \& van Winckel J. The influence of relative age on success and dropout in male soccer players. Am J Hum Biol 10: 791-798, 1998.

49. Helsen WF, van Winckel J, and Williams MA. The relative age effect in youth soccer across Europe. J Sports Sci 23: 629-636, 2005.

50. Herbison JD, Martin LJ, \& Sarkar M. Achievement despite adversity: A qualitative investigation of undrafted national hockey league players. Sport Psych 33: 285-294, 2019.

51. Hirose N. Relationships among birth-month distribution, skeletal age and anthropometric characteristics in adolescent elite soccer players. J Sports Sci 27: 1159-1166, 2009.

52. Hollings SC, Hume PA, and Hopkins WG. Relative-age effect on competition outcomes at the World Youth and World Junior Athletics Championships. Eur J Sport Sci 14: 456-461, 2014.

53. Holt NL and Dunn JGH. Towards a grounded theory of the psychosocial competencies and environmental conditions associated with soccer success. J Appl Sport Psychol 16: 199-219, 2004.

54. Jeffreys I, Huggins S, and Davies N. Delivering a gamespeed-focused speed and agility development program in an English Premier League soccer academy. Strength Cond J 40: 23-32, 2018.

55. Jones BD, Lawrence GP, and Hardy L. New evidence of relative age effects in "super-elite" sportsmen: A case for the survival and evolution of the fittest. J Sports Sci 36: 697-703, 2018.

56. Johnson A, Farooq A, and Whiteley R. Skeletal maturation status is more strongly associated with academy selection than birth quarter. Sci Med Foot 1: 157-163, 2017. 
57. Juffer P, Furrer R, Gonzalez-Freire M, Santiago C, Verde Z, Serratosa L, Morate FJ, distributions in top-level soccer players: A role for ACE? Int J Sports Med 30: 387-392, 2009.

58. Kelly AL, Wilson MR, Gough LA, Knapman H, Morgan P, Cole M, Jackson DT, \& Williams CA. A longitudinal investigation into the relative age effect in an English professional football club: The 'underdog hypothesis'. Sci Med Football, 1-8, 2019.

59. Khamis HJ and Guo S. Improvement in the Roche-Wainer-Thissen stature prediction model: A comparative study. Am J Hum Biol 5: 669-679, 1993.

60. Khamis HJ and Roche AF. Predicting adult stature without using skeletal age: The Khamis-Roche method. Pediatrics 94: 504-507, 1994.

61. Le Gall F, Carling C, Williams M, and Reilly T. Anthropometric and fitness characteristics of international, professional and amateur male graduate soccer players from an elite youth academy. J Sci Med Sport 13: 90-95, 2010.

62. Lloyd RS and Oliver JL. The Youth Physical Development model: A new approach to long-term athletic development. Strength Cond J 34: 61-72, 2012.

63. MacNamara A and Collins D. Development and initial validation of the Psychological Characteristics of Developing Excellence Questionnaire. J Sports Sci 29:1273-1286, 2011.

64. Malina RM, Bouchard C, and Bar-Or, O. Growth, Maturation, and Physical Activity (2nd Ed.). Champaign, IL: Human Kinetics, 2003.

65. Malina RM, Cumming SP, Morano PJ, Barron M, and Miller SJ. Maturity status of youth football players: A noninvasive estimate. Med Sci Sports Exerc 37: 1044-1052, 2005.

66. Malina RM, Dompier TP, Powell JW, Barron MJ, and Moore MT. Validation of a noninvasive maturity estimate relative to skeletal age in youth football players. Clin J Sport Med 17: 362-368, 2007.

67. Malina RM, Eisenmann JC, Cumming SP, Ribeiro B, and Aroso J. Maturityassociated variation in the growth and functional capacities of youth football (soccer) players 13-15 years. Eur J Appl Physiol 91: 555-562, 2004.

68. Malina RM, Penareyes ME, Eisenmann JC, Horta L, Rodrigues J, and Miller R. Height, mass and skeletal maturity of elite Portuguese soccer players aged 11-16 years. $J$ Sports Sci 18: 685-693, 2000.

69. Malina RM, Ribeiro B, Aroso J, and Cumming SP. Characteristics of youth soccer players aged 13-15 years classified by skill level. Br J Sports Med 41: 290-295, 2007.

70. Malina RM, Chamorro M, Serratosa L, and Morate F. TW3 and Fels skeletal ages in elite youth soccer players. Ann Hum Biol 34: 265-272, 2019.

71. Malina RM, Rogol AD, Cumming SP, Coelho-e-Silva MJ, and Figueiredo AJ. Biological maturation of youth athletes: Assessment and implications. Br J Sports Med 49: 852-859, 2015. 
72. Malina RM, Cumming SP, Rogol AD, Coelho-E-Silva MJ, Figueirdeo AJ, Konarski Sports Med 49: 1671-1685, 2019.

73. Mann DL and van Ginneken PJMA. Age-ordered shirt numbering reduces the selection bias associated with the relative age effect. J Sports Sci 35: 784-790, 2017.

74. Martinez-Santos R, Castillo D, and Los Arcos A. Sprint and jump performances do not determine the promotion to professional elite soccer in Spain, 1994-2012. J Sports Sci 34: 2279-2285, 2016.

75. Massa M, Costa EC, Moreira A, Thiengo CR, Lima MR, Marquez WQ, and Aoki MS. The relative age effect in soccer: A case study of the Sao Paulo Football Club. Rev Bras Cineantropom Desempenho Hum 16: 399-405, 2014.

76. McCarthy $\mathrm{N}$ and Collins $\mathrm{D}$. Initial identification \& selection bias versus the eventual confirmation of talent: Evidence for the benefits of a rocky road? J Sports Sci 32: 1604-1610, 2014.

77. McCarthy N, Collins D, and Court D. Start hard, finish better: Further evidence for the reversal of the RAE advantage. J Sports Sci 34: 1461-1465, 2016.

78. Meylan C, Cronin J, Oliver J, and Hughes M. Talent identification in soccer: The role of maturity status on physical, physiological and technical characteristics. Int J Sports Sci Coach 5: 571-592, 2010.

79. Micheli ML, Gulisano M, Morucci G, Punzi T, Ruggiero M, Ceroti M, Marella M, Castellini E, and Pacini S. Angiotensin-converting enzyme/vitamin D receptor gene polymorphisms and bioelectrical impedance analysis in predicting athletic performances of Italian young soccer players. J Strength Cond Res 25: 2084-2091, 2011.

80. Mirkov DM, Nedeljkovic A, Kukolj M, Ugarkovic D, and Jaric S. Evaluation of the reliability of soccer-specific field tests. J Strength Cond Res 22: 1046-1050, 2008.

81. Morley D, Morgan G, McKenna J, and Nicholls AR. Developmental contexts and features of elite academy football players: Coach and player perspectives. Int J Sports Sci Coach 9: 217-232, 2014.

82. Musch J and Hay R. The relative age effect in soccer: Cross-cultural evidence for a systematic discrimination against children born late in the competition year. Sociol Sport $J$ 16: 54-64, 1999.

83. Nakata H and Sakamoto K. Relative age effects in Japanese baseball: A historical analysis. Percept Mot Skills 117: 276-289, 2013.

84. Ostojic SM, Castagna C, Calleja-Gonzalez J, Jukic I, Idrizovic K, and Stojanovic M. The biological age of 14-year-old boys and success in adult soccer: Do early maturers predominate in the top-level game? Res Sports Med 22: 398-407, 2014.

85. Pearson DT, Naughton GA, and Torode M. Predictability of physiological testing and the role of maturation in talent identification for adolescent team sports. J Sci Med Sport 9: 277-287, 2006. 
86. Philippaerts RM, Vaeyens R, Janssebs M, van Renterghem B, Matthys D, Craen R, Bourgois J, Vrijens J, Beunen, and Malina R. The relationship between peak height velocity and physical performance in youth soccer players. J Sports Sci 24: 221-230, 2006.

87. Reilly T, Bangsbo J, and Franks A. Anthropometric and physiological predispositions for elite soccer. J Sports Sci 18: 669-683, 2000.

88. Reilly T, Williams AM, Nevill A, and Franks A. A multidisciplinary approach to talent identification in soccer. J Sports Sci 18: 695-702, 2000.

89. Robertson S, Woods C, and Gastin P. Predicting higher selection in elite junior Australian Rules football: The influence of physical performance and anthropometric attributes. J Sci Med Sport 18: 601-606, 2015.

90. Rostan SM. Studio learning: Motivation, competence, and the development of young art students' talent and creativity. Creativity Res J 22: 261-271, 2010.

91. Ryan D, Lewin C, Forsythe S, and McCall A. Developing world-class soccer players: An example of the academy physical development program from an English Premier League team. Strength Cond J 40: 2-11, 2018.

92. Sarmento H, Anguera MT, Pereira A, and Araujo D. Talent identification and development in male football: A systematic review. Sports Med 48: 907-931, 2018.

93. Schorer J, Cobley S, Busch D, Brautigam H, and Baker J. Influences of competition level, gender, player nationality, career stage and playing position on relative age effects. Scand J Med Sci Sports 19: 720-730, 2009.

94. Singer RN and Janelle CM. Determining sport expertise: From genes to supremes. $J$ Sport Psychol 30: 117-150, 1999.

95. Taylor JM, Cunningham L, Hood P, Thorne B, Irvin G, and Weston M. The reliability of a modified 505 test and change-of-direction deficit time in elite youth football players. Sci Med Football 3: 157-162, 2018.

96. The FA. England Coaching Pathway. 2016. Available at: http://www.thefa.com/news/2016/oct/07/discover-the-coaching-pathway. Accessed June 22, 2019.

97. The FA. England DNA. 2014. http://www.thefa.com/news/2014/dec/04/england-dnalaunch. Accessed June 22, 2019.

98. The FA. The Playing and Coaching Philosophy of England Teams. 2019. Available at: http://www.thefa.com/learning/england-dna. Accessed June 22, 2019.

99. The Premier League. Elite Player Performance Plan. 2011. Available at: https://www.premierleague.com/youth/EPPP. Accessed June 22, 2019.

100. The Premier League. Elite Performance. 2019. Available at: https://www.premierleague.com/youth/elite-performance. Accessed December 10, 2019. 
101. Till K, Cobley S, Wattie N, O'Hara J, Cooke C, and Chapman C. The prevalence, influential factors and mechanisms of relative age effects in UK rugby league. Scand $\mathrm{J}$ Med Sci Sports 20: 320-329, 2010.

102. Tribolet R, Watsford ML, Coutts AJ, Smith C, \& Fransen J. From entry to elite: The relative age effect in the Australian football talent pathway. J Sci Med Sport 22: 741-745, 2019.

103. Turnnidge J, Hancock DJ, and Cote J. The influence of birth date and place of development on youth sport participation. Scand J Med Sci Sports 24: 461-468, 2014.

104. Ulbricht A, Fernandez-Fernandez J, Mendez-Villanueva A, and Ferrauti A. The relative age effect and physical fitness characteristics in German male tennis players. $J$ Sci Med Sport 14: 634-42, 2015.

105. Vaeyens R, Lenoir M, Williams MA, and Philippaerts RM. Talent identification and development programmes in sport: Current models and future directions. Sports Med 38: 703-714, 2008.

106. van Den Honert R. Evidence of the relative age effect in football in Australia. $J$ Sports Sci 30: 1365-1374, 2012.

107. van Rossum JHA. Relative age effect revisited: Findings from the dance domain. Percept Mot Skills 102: 302-308, 2006.

108. Vandendriessche JB, Vaeyens R, Vandorpe B, Lenoir M, Lefevre J, and Philippaerts RM. Biological maturation, morphology, fitness, and motor coordination as part of a selection strategy in the search for international youth soccer players (age 15-16 years). $J$ Sports Sci 30: 1695-1703, 2012.

109. Votteler A and Honer O. Cross-sectional and longitudinal analyses of the relative age effect in German youth football. Sportwissenschaft 47: 194-204, 2017.

110. Votteler A and Honer O. The relative age effect in the German Football TID Programme: Biases in motor performance diagnostics and effects on single motor abilities and skills in groups of selected players. Eur J Sport Sci 14: 433-442, 2014.

111. Williams AM and Reilly T. Talent identification and development in soccer. $J$ Sports Sci 18: 657-667, 2000.

112. Williams CA, Oliver JL, and Faulkner J. Seasonal monitoring of sprint and jump performance in a youth soccer academy. Int J Sport Physiol 6: 264-275, 2011.

113. Wong PL, Chamari K, Dellal A, and Wisloff U. Relationship between anthropometric and physiological characteristics in youth soccer players. J Strength Cond Res 23: 1204$1210,2009$. 
Table 1. Selected examples of key literature focussing on physical performance and the talent identification and development processes in male youth soccer.

Authors Aims Sample

Gouvea et al.

Compare maturation, body composition, and physical fitness between youth soccer players with different technical skill levels.

62 youth soccer players (aged 11-17 years) from two semi-professional soccer clubs in Brazil.

Evaluate the anthropometric, speed, and endurance characteristics of youth soccer players, comparing players who obtained a professional contract at aged 18 years with those that did not.

Examine the impact of physical performance on the top playing level attained by soccer players.

235 players enrolled in the reserve team of a Spanish La Liga soccer club from 1994-2012.

Aims were twofold; 1) Expose the

anthropometrical, physical performance, and motor coordination characteristics that influence dropout from a high-level soccer training program. 2) Cross-sectional data of anthropometry, physical performance, and motor coordination were retrospectively explored to investigate which characteristics influence

achieving professional status.

Compare the changes in body size,

Carling et al. estimated fatness, skeletal maturation, and functional characteristics of yo soccer players on entry into an academy from 1992-2003.
443 academy soccer players from an

English professional soccer club.
1) 388 Belgian youth soccer players (aged 8-16 years) participated in the mixed-longitudinal study. 2) 72 Belgian youth soccer players participated in the future contract status and first-team playing time study.

\section{8 youth soccer players from a} regional academy in France.
Study design Players were categorised dichotomously in more skilled $(\mathrm{n}=31$ ) and less skilled $(\mathrm{n}=31)$ groups based on three specific technical tests. Chronological and skeletal age, time of practice, body composition, and four physical fitness tests were performed for comparisons.

Players undertook anthropometric (height and body mass), speed (10 and $20 \mathrm{~m}$ sprint), and endurance (YoYo intermittent endurance test level 2) assessments from 2005-2012.

Outcomes

More skilled subjects showed higher time of practice and greate performance sit-ups, squat jump, CMJ, and Yo-Yo test compared to the less skilled subjects.

Significant differences were observed between 'professional' and 'academy'

players for $10 \mathrm{~m}$ and $20 \mathrm{~m}$ speed at

U16 and U18, and Yo-Yo performance at U18.

Players performed physical tests $(5 \mathrm{~m}$ and $15 \mathrm{~m}$ sprint times and CMJ) and were compared against the highes competitive-level they achieved; Spanish first $(\mathrm{n}=39)$ and second divisions $(\mathrm{n}=36)$ and semiprofessional $(\mathrm{n}=160)$. Players were also classified according to their playing positions.

1) Youth soccer players were assigned to either a 'club group' or a 'dropout group' and were examined against the relevant characteristics. 2) Contract vs. no contract groups and first-team playing time were examined against the relevant characteristics.

Annual selections grouped across time, playing position, and by eventual status in the sport were compared. Data at entry into the academy included skeletal age
Sprint and jump performances are not a relevant physical parameter to promote to the top level of soccer in Spain; except for one in six of the playing positions (central defenders).

1) Club players outperformed their dropout peers for motor coordination, soccer-specific aerobic endurance, and speed. Anthropometry and estimated maturity status did not discriminate between club and dropout players. 2) Contract player jumped further and had faster times for a $5 \mathrm{~m}$ sprint compared to no contract players.

With few exceptions (but notably estimated $\mathrm{VO}_{2 \max }$ ), results for playe size, functional characteristics, and skeletal maturation did not differ among years. Distributions of players 
(Greulich-Pyle method), height, weight, relative fatness, four field

tests of functional capacities (aerobic,

anaerobic, power, and speed), and

quadriceps concentric strength.
Compare physiological characteristics

Gonaus and

Muller (2012)

among academy soccer players in

terms of subsequent career

progression ('drafted' vs. 'nondrafted'). $\sim 3,000$ Austrian soccer academy players (aged 14-17 years).
In a longitudinal design (2001-2010) players passed through ten fitness tests at four age levels; U14 $(\mathrm{n}=410)$ $\mathrm{U} 15(\mathrm{n}=504), \mathrm{U} 16(\mathrm{n}=456)$, and U17 years $(n=272)$. by skeletal maturity status and within each playing position also did not differ between years.

Superior performances for drafted players were observed in all fitness components (speed, power,

flexibility, coordination, and

endurance) and age levels. Follow up discriminant analyses confirmed that a combination of the shuttle sprint, 20 $\mathrm{m}$ sprint, and medicine ball throw correctly classified 62.7 to $66.2 \%$ of the players.

Sprint performance changes tended to be greatest during the early teenage years, with observed changes performance characteristics of youth soccer players over a three year 200 youth soccer players across five age squads (U12-U16) from an English Football League academy.

Sprint performance (10 and $30 \mathrm{~m}$ ) and MJ height were assessed at six month intervals.

Participants were assessed over an eleven year period (1994-2005)

Players were grouped according to

Compare anthropometric and fitness performance data from graduate male

Le Gal et al. youth players from a soccer academy, who on leaving the institution were

161 French youth soccer players who (2010) either successful or not in progressing Institute of Football) to higher standards of play.

whether they achieved internation or professional status or remained amateur. Measures were taken acros three age levels (aged U14, U15, and U16 years). Players were assessed

using standard measures of anthropometric and fitness characteristics.

Describe the anthropometric and physiological characteristics of young soccer players which were associated with being successful or not as soccer players.
194 Spanish youth soccer players (aged 14-17 years).
Somatotype and body composition was calculated by measuring skinfolds, limb circumferences, and joint diameters. $\mathrm{VO}_{2 \max }$ was estimated by the Astrand Test. Sprint, jump, and endurance tests were also performed. exceeding the smallest worthwhile effect ( $1.0 \%$ for 10 and $30 \mathrm{~m}$ sprints). Changes in jump performance were above the smallest worthwhile effect of $1.8 \%$ for all but one interval.

Significant differences were reported or maturity status, body mass, height, peak concentric torque, maximal anaerobic power, sprint, and $\mathrm{CM}$ performance between internationals/professionals and amateurs, with results further dependant on age level and playing position.

These results indicate that around the time of puberty, parameters associated with physical maturity such as height, size, speed, $\mathrm{VO}_{2 \max }$, or chronological age, are important to determine the success of a soccer player. At older ages, other factors such as agility seem to be more such as ag 
Philippaerts et al.

(2006)
Examine the longitudinal changes in height, weight, and physical performance in youth soccer players.
33 Flemish youth soccer players (aged 10-13 years) from the Ghent Youth Soccer Project.
Longitudinal changes were studied ver a five year period. Peak height velocity and peak weight velocity were determined using non-smoothed polynomials.
Peak weight velocity occurred, on average, at the same age as peak height velocity. Balance, speed of limb movement, trunk strength, upper-body muscular endurance, explosive strength, running speed and agility, cardiorespiratory endurance, and anaerobic capacity showed peak development at peak height velocity. 
Table 2. Selected examples of key literature focussing on growth and maturation and the talent identification and development processes in male youth soccer.

\section{$\begin{array}{llll}\text { Authors } & \text { Aims } & \text { Sample } & \text { Study design }\end{array}$}

\section{Anthropometric measurements,}

physical tests (sprint, agility,

endurance, and jump), and maturity

status (age at PHV) were recorded

Bidaurrazaga-

Letona et al.

Identify the factors that are important for the identification and selection of youth soccer players.

94 youth soccer players from the U13 and U15 levels belonging to a professional Spanish La Liga club.
Compare variation in size, function,
Gouvea et al

(2016) and sport-specific technical skills of differences in biological maturity status. youth soccer players associated with
60 youth soccer players of U14 and U17 levels from semi-professional soccer clubs in Brazil.
Players completed anthropometric and body composition measurements as well as motor and soccer-specific technical skill tests. Skeletal maturity was determined by skeletal age. Athletes of both levels were classified as early, on-time, or late-maturing, according to the difference between chronological age and skeletal age.

At the age of 14 years, biological age using skeletal age rates was determined, and participants were categorized as early maturers (EaM), normal maturers (NoM), and late

Determine the prevalence of different 55 youth soccer players (aged 14
Ostojic et al maturational groups among youth soccer players, and to track them for competence in adult performance. years) playing in Serbian youth soccer

Division I were followed over an eight year period. maturers described as 'elite' if an individual played for clubs competing in top-five international soccer leagues (La Liga, Premier League, Bundesliga, Serie A, and Ligue 1), and/or has become a member of an adult national team.

Vandendriessche

Examine biological maturation,

et al. (2012) coordination as part of a selection
78 Belgian international youth soccer

Report the morphology (height,

weight, body fat, and body mass over four seasons. Comparisons were performed among new players joining the club (Enter players, $n=15$ ), players progressing to the next age category (Club players, $\mathrm{n}=54$ ), and players leaving the club (Deselected players, $\mathrm{n}=25$ ).

Outcomes

Better physical performance and improvements observed during the season in performance were found to be one of the main factors for U13 players to continue. In the U15 group, although body size, maturation, and physical performance appeared to be the most important characteristics for being identified to play in the club, Club players demonstrated better improvements during the season. Body mass and height were lower in the late athletes, independent of age level. Differences in adiposity were found only between athletes of the U14. Significant differences were identified on aerobic endurance in U14 (early<on time), upper limbs muscular strength (late<early), and flexibility in U17 (late<on time). In contrast, players in each age group of contrasting maturity status do not differ in soccer-specific skills.

$3.8 \%$ were categorised as EaM, $35.4 \%$ as NoM, and $20.8 \%$ as LaM. A significant difference in biological age was found among maturational groups at aged 14 years, with

$\mathrm{EaM}>\mathrm{NoM}>\mathrm{LaM}$. When assessed for adult soccer competence, $33.3 \%$ of participants (16 out of 48 players) succeed in achieving 'elite' level. 'Elite' soccer competence acquired $60.1 \%$ players from the group of $\mathrm{LaM}$ $38.1 \%$ from NoM, and $11.8 \%$ from EaM.

The more mature players (U16 and U17) possessed higher morphological index), fitness (strength, speed, agility, measures and outperformed their later 
strategy in the search for international

youth soccer players.

Compare variation in size, function, sport-specific skill, and goal

Figueiredo et al. (2009)

orientation associated with difference in biological maturity status of youth soccer players within two competitive age groups.
159 youth soccer players from five clubs in Portugal competing in two age groups; U11-12 $(n=87)$ and 13-14 years $(n=72)$
Examine the relationship between anthropometric and physiological performances among youth soccer players and the positional differences for these variables.
70 U14 youth soccer players

(goalkeeper $\mathrm{n}=10$, defender $\mathrm{n}=20$, midfielder $n=25$, and forward $=15$ ) who were members of regional representative teams competing at the highest level of competition for their age category in Hong Kong.

Establish the anthropometric and physiological profiles of young 'nonelite' soccer players according to their playing position, and to determine their relevance for the selection process.
241 youth soccer players who were members of the Getxo Arenas Club (Spain). Players, aged 14-21 years, were classified into the following groups; forwards $(\mathrm{n}=56)$, midfielder $(n=79)$, defenders $(n=77)$, and goalkeepers $(n=29)$. and flexibility), and soccer-specific and non-specific motor coordination skills of international youth soccer players with varying biological maturity status.

Weight, height, sitting height, four skinfolds, four functional capacities, four soccer skills, and goal orientation were measured. Skeletal maturity wa assessed using the Fels method. Each player was classified as late, on time, or early maturing based on the difference between skeletal and chronological ages.

\section{Body mass was significantly} correlated with ball shooting speed and $30 \mathrm{~m}$ sprint time. Body height was

maturing peers (U16 Futures and U17 Futures) on almost all fitness tests.

However, soccer-specific and nonspecific motor coordination tests did not distinguish the more mature players from the later maturing players in both age groups.

Late, on time, and early maturing players are represented among aged 11-12 years, but late maturing boys are under-represented among aged 1314 years. Players in each age group advanced in maturity are taller and heavier than those on time and late in skeletal maturity, but players of contrasting maturity status do not differ, with few exceptions, in functional capacities, soccer-specific skills, and goal orientation. jump height, $10 \mathrm{~m}$ and $30 \mathrm{~m}$ sprint times, Yo-Yo intermittent endurance run distance, and $\mathrm{VO}_{2}$ max. Body mass index was significantly correlated with ball shooting speed, $30 \mathrm{~m}$ sprint time,

Hoff test dribble distance, Yo-Yo intermittent endurance run distance, submaximal running cost, $\mathrm{VO}^{2} \max$, and the corresponding running time. Anthropometric variables of

participants (height, weight, body mass index, six skinfolds, four

diameters, and three perimeters) were measured. Also, their somatotype and body composition (weight and percentages of fat, bone, and muscle) were calculated. Participants performed the Astrand test to estimate endurance test, sprint tests ( $30 \mathrm{~m}$ flat
This provides a scientific rationale behind the coaches' practice of selecting youth soccer players according to their anthropometry for hort-term benefits; such as heavier players for higher ball shooting speed and $30 \mathrm{~m}$ sprint ability as an example. However, this does not justify such practice in the long-term process of player development.

Forwards were the leanest, presenting the highest percentage of muscle. They were the best performers in all the physiological tests, including endurance, velocity, agility, and power. In contrast, goalkeepers were found to be the tallest and the heaviest players. They also had the largest fat skinfolds and the highest fat percentage, but their aerobic capacity was the lowest. In the selection 
and $30 \mathrm{~m}$ with ten cones), and three jump tests (squat jump, CMJ, and drop jump). (2007)

Evaluate the growth, maturity status, soccer players grouped by skill level.
Malina et al. and functional capacity of youth
69 youth soccer players (aged 13-15 years) from clubs that competed in the highest division for their age group in Portugal. process, agility and the jump tests were the most discriminating for forwards. In contrast, agility, height, and endurance were the key factors for midfielders. The defenders group was characterised by a lower quantity of fat.

Height and body mass of players were measured and stage of pubic hair was assessed at clinical examination. Years of experience in football were

obtained at interview. Three tests of

functional capacity were administered; dash, vertical jump, and endurance shuttle run. Performances on six soccer- specific tests were converted to a composite score which was used to classify players into quintiles of skill.

Height and weight were measured and stage of pubic hair development was assessed at clinical examination. Three tests of functional capacity were administered; $30 \mathrm{~m}$ dash (running speed), vertical jump (explosive power), and a Yo-Yo intermittent endurance test (aerobic resistance).

\section{status to varition in the function capacities of youth soccer players. \\ (2004)} national division.

69 youth soccer players (aged 13-15 years) from three clubs which classified by skill do not differ in age,
Heights and masses were compared to US reference values, and skeletal age and chronological age were

contrasted. The players were also classified as late, on time, and early maturers on the basis of differences between skeletal and chronological age, with the average category including boys with skeletal age within $+/-1$ year of chronological age.
The only difference between the highest and lowest skill groups wa the endurance shuttle run. Thus, youth soccer players aged 13-15 years experience, body size, speed, and power, but differ in aerobic endurance; specifically at the extremes of skill.

Stage of puberty, body size, and years of training accounted for $21 \%$ to $50 \%$ of the variance in the three tasks.

Sexual maturity status was the primary contributor to the variance in the intermittent shuttle run, whereas weight and height were the primary contributors to the explained variance in the $30 \mathrm{~m}$ dash and vertical jump, respectively.

The proportion of late maturing youth soccer players decreased with increasing chronological age. Among players aged $11-12$ years, the percentages of late and early maturing boys were equal at $21 \%(\mathrm{n}=13)$. Among players aged 13-14 years, the percentages of late and early maturing boys were $7 \%(n=2)$ and $38 \%(n=11)$ respectively, while among players aged 15-16 years, the percentages of late and early maturing boys were $2 \%$ $(n=1)$ and $65 \%(n=28)$, respectively. 

Table 3. Selected examples of key literature focussing on the RAE and the talent identification and development processes in male youth soccer.

Author(s) Aims $\quad$ Sample

Aims were twofold; 1) Provide further 1) 556 youth soccer players from an professional contracts awarded to test of the RAE. 2) Examine the BQ of participated in the first study. 2) 364 academy graduates.
Kelly et al.

(2019) youth soccer players from an English professional football club participated in the second study.

841 'elite' youth soccer players who were participants in the UEFA

European Soccer Championship in different levels.
Study design

1) Participants were included who were either current or previously registered academy players across twelve seasons. 2) Participants were included who were previously registered academy players, to assess which graduates achieved a senior professional contract at aged 18 years across eleven seasons.

\section{Gonzalez}

Bertomeu

Identify the existence of RAE in

European soccer players
Votteler and

Honer (2017)

Investigate the location of RAE differences between consecutive age categories and competition levels and

RAE emergence through talent

selection procedures.
35,390 youth soccer players from the

German talent development (2010/2011-2012/2013). programme from three seasons following levels; professional category $(n=368)$, U21 $(n=184)$, U19 $(n=144)$, and $\mathrm{U} 17(\mathrm{n}=145)$.
The groups were split into the

\section{Outcomes}

These findings are indicative that the RAE continues to manifest within an academy setting. Interestingly however, the 'underdog hypothesis' shows BQ4s were approximately four times more likely to achieve senior professional status compared to BQ1s.

The RAE was not evident in the professional teams analysed, however it was present in the three lower categories analysed (youth categories), with its influence being greater on younger age categories (U17) The longitudinal analyses of talent selection procedures revealed an RAE increase for players newly selected for

Cross-sectional analyses showed a consistent increase of RAEs over four ascending competition levels and slightly increasing RAEs from age categories U12-U15, with a subsequent decrease until U19.
Examine if anthropometry and performance were different amongst older and younger soccer players born 88 Spanish youth soccer players (aged 9-10 years).
Anthropometric measurements, physical tests (sprint, agility, endurance test, jump, and hand dynamometry), and the estimation of the maturity status were assessed. higher competition levels and no change in RAE extent for players retained across consecutive age categories at the same competition level.

Chronological age was the most important variable in the agility test and the overall score, after the skinfolds (negative effect).

Differences were also found in anthropometry and physical performance amongst older and younger pre-pubertal soccer players. The article finds a large effect of the

\section{Gonzalez-}

Villora et al.

(2015)
Examine the RAE in a male Premier

League in Latin America - the

Argentinian ' $A$ ' league. $\sim 3,000$ Argentinian youth soccer players.
Examine the BQ distribution amongst youth and senior teams during the period 2000-2012. player's relative age and their prospect of becoming a professional. The effect evaporates once a set of measures are employed to compare professional players with one another. 


\begin{tabular}{|c|c|c|c|c|}
\hline $\begin{array}{l}\text { Helsen et al. } \\
(2012)\end{array}$ & $\begin{array}{l}\text { Compare the birth date distributions of } \\
\text { professional soccer players in ten } \\
\text { European countries over a ten year } \\
\text { period involving the } 2000 / 2001 \text { and } \\
2010 / 2011 \text { competitive seasons. }\end{array}$ & $\begin{array}{l}\sim 9,200 \text { players across ten European } \\
\text { countries. }\end{array}$ & $\begin{array}{l}\text { Analyse the differences between the } \\
\text { observed and expected BQ } \\
\text { distributions across selection years. }\end{array}$ & $\begin{array}{l}\text { Results indicated no change in the } \\
\text { RAE over the past ten years in } \\
\text { professional soccer, emphasising the } \\
\text { robust nature of this phenomenon. }\end{array}$ \\
\hline $\begin{array}{l}\text { Helsen et al. } \\
(2005)\end{array}$ & $\begin{array}{l}\text { Examine the potential asymmetries in } \\
\text { the birth date distributions of youth } \\
\text { soccer players. }\end{array}$ & $\begin{array}{l}2,175 \text { players across ten European } \\
\text { countries. }\end{array}$ & $\begin{array}{l}\text { The BQ distribution of players } \\
\text { representing national youth teams in } \\
\text { international competitions, alongside } \\
\text { the birth dates of those representing } \\
\text { professional club teams in } \\
\text { international youth tournaments, were } \\
\text { examined. }\end{array}$ & $\begin{array}{l}\text { The results showed an } \\
\text { overrepresentation of players born in } \\
\text { BQ1 (from January to March) for all } \\
\text { the national youth selections at the } \\
\text { U15, U16, U17, and U18 age levels, } \\
\text { as well as for the UEFA U16 } \\
\text { tournaments and Meridian Cup. }\end{array}$ \\
\hline $\begin{array}{l}\text { Glamser and } \\
\text { Vincent (2004) }\end{array}$ & $\begin{array}{l}\text { Investigate the RAE among a } \\
\text { population of youth soccer players } \\
\text { born in } 1984 \text {. }\end{array}$ & 147 American youth soccer players. & $\begin{array}{l}\text { Examine the BQ distribution amongst } \\
\text { youth soccer players considered by the } \\
\text { Olympic Development Program to be } \\
\text { the most talented in the US. }\end{array}$ & $\begin{array}{l}\text { Almost } 70 \% \text { of players were born in } \\
\text { the first half of the year. Players were } \\
\text { three times as likely to have a birthday } \\
\text { in the first BQ compared to the last } \\
\text { BQ, and were over five times as likely } \\
\text { to have a January birthday as a } \\
\text { December birthday. }\end{array}$ \\
\hline $\begin{array}{l}\text { Musch and Hay } \\
\text { (1999) }\end{array}$ & $\begin{array}{l}\text { Attempt to replicate the RAE in a } \\
\text { cross-cultural comparison. }\end{array}$ & $\begin{array}{l}\sim 1,500 \text { youth soccer players across } \\
\text { four international counties. }\end{array}$ & $\begin{array}{l}\text { For each country under consideration, } \\
\text { a sample consisting of all players in } \\
\text { the highest professional soccer league } \\
\text { was investigated. For each league, the } \\
\text { distribution of professional players' } \\
\text { birthdays was computed by month. } \\
\text { These birthday distributions were then } \\
\text { compared with that of the general } \\
\text { population. }\end{array}$ & $\begin{array}{l}\text { A strong RAE in professional soccer } \\
\text { was found in Germany, Japan, Brazil, } \\
\text { and Australia, showing that the effect } \\
\text { is independent of different cut-off } \\
\text { dates and a variety of climatic and } \\
\text { sociocultural factors. }\end{array}$ \\
\hline $\begin{array}{l}\text { Barnsley et al. } \\
\text { (1992) }\end{array}$ & $\begin{array}{l}\text { Examine the existence of the RAE at } \\
\text { World Cup competitions. }\end{array}$ & $\begin{array}{l}\sim 1,100 \text { 'elite' soccer players who were } \\
\text { participants in a World Cup at } \\
\text { different levels. }\end{array}$ & $\begin{array}{l}\text { The groups were split into the } \\
\text { following levels; Senior World Cup, } \\
\text { U20 World Cup, and U17 World Cup. }\end{array}$ & $\begin{array}{l}\text { Whilst there was a small } \\
\text { overrepresentation of players born in } \\
\text { the first half of the year compared to } \\
\text { the second half of the year at the } \\
\text { Senior World Cup, the effect was } \\
\text { considerably stronger at the U17 and } \\
\text { U20 tournaments. }\end{array}$ \\
\hline
\end{tabular}

